\title{
UPAYA MENINGKATKAN HASIL BELAJAR SISWA PADA MATA PELAJARAN IPS MELALUI MODEL PEMBELAJARAN MAKE A MATCH
}

\author{
Riris Nurkholidah Rambe ${ }^{1}$, Amelia Putri ${ }^{2}$ \\ Dosen Universitas Islam Negeri Sumatera Utara ${ }^{1}$, Mahasiswa Prodi Pendidikan Guru Madrasah Ibtidaiyah ${ }^{2}$ \\ Email: ririsnurkholidah@uinsu.ac.id, ameliaputri@gmail.com
}

\begin{abstract}
Abstrak: Penelitian ini merupakan penelitian tindakan kelas (PTK). Subjek penelitian ini adalah siswa kelas IV MIS Al-Jam'iyatul Washliyah Desa Nagur yang berjumlah 28 orang. Penelitian ini bertujuan untuk mengetahui: (1) Hasil belajar siswa pada mata pelajaran IPS sebelum diterapkan model pembelajaran make a match. (2) Penerapan model pembelajaran make a match yang dapat meningkatkan hasil belajar siswa pada mata pelajaran IPS. (3) Hasil belajar siswa pada mata pelajaran IPS setelah diterapkan model pembelajaran make a match.Temuan penelitian ini adalah sebagai berikut: (1) Hasil belajar siswa pada mata pelajaran IPS sebelum diterapkan model pembelajaran make a match masih tergolong sangat rendah. (2) Penerapan model pembelajaran make a match dilaksanakan dua siklus, setiap siklus berisi tindakan-tindakan untuk mengembangkan skenario pembelajaran yang telah ditetapkan. Selama diterapkan model pembelajaran make a match siswa terlihat aktif dan lebih mudah menerima pembelajaran yang telah diajarkan. (3) Hasil belajar siswa pada mata pelajaran IPS setelah diterapkan model pembelajaran make a match meningkat dan tergolong tinggi. Hasil penelitian ini adalah pada tes awal frekuensi ketuntasan sebesar $7,14 \%$ meningkat ke test siklus I menjadi $60,71 \%$. Sedangkan dari siklus I sebesar $60,71 \%$ meningkat ke test siklus II menjadi 96,42\%. Dengan demikian, model pembelajaran make a match pada mata pelajaran IPS dapat meningkatkan hasil belajar siswa.
\end{abstract}

Kata Kunci : Model Pembelajaran Make a match dan Hasil Belajar

\section{A. PENDAHULUAN}




\section{NIZHAMIYAH}

Pendidikan adalah proses pengubahan sikap dan tata laku seseorang atau sekelompok orang dalam usaha mendewasakan manusia melalui pengajaran dan pelatihan. ${ }^{1}$ Pengajaran adalah proses pemberian ilmu pengetahuan kepada anak didik yang berasal dari pemberian pengertian, pemahaman, dan penghayatan sampai pada pengalaman kecerdasan akal pikiran atau intektualitasnya. ${ }^{2}$

Pendidikan merupakan proses pemberian bimbingan kepada anak didik melalui pengajaran agar memiliki pengetahuan, keterampilan dan sikap yang baik sebagai bekal dalam menjalankan aktivitas hidupnya.

Menurut UU No. 20 tahun 2003 (dalam Hasbullah) pendidikan adalah usaha sadar dan terencana untuk mewujudkan suasana belajar dan proses pembelajaran agar peserta didik secara aktif mengembangkan potensi dirinya untuk memiliki kekuatan spiritual keagamaan, pengendalian diri, kepribadian, kecerdasan, akhlak mulia, serta keterampilan yang diperlukan dirinya, masyarakat, bangsa, dan negara. ${ }^{3}$ Pendidikan merupakan suatu kegiatan sistematis dan terarah yang memiliki tujuan untuk meningkatkan kualitas kahidupan manusia. ${ }^{4}$ Pendidikan nasional berfungsi mengembangkan kemampuan dan membentuk watak serta peradaban bangsa yang bermartabat dalam rangka mencerdaskan kehidupan bangsa, bertujuan untuk mengembangkan potensi peserta didik agar menjadi manusia yang beriman dan bertakwa kepada Tuhan Yang Maha Esa, berakhlak mulia, sehat, berilmu, cakap, kreatif, mandiri, dan menjadi warga negara yang demokratis serat bertanggung jawab. ${ }^{5}$

Menurut UNESCO (dalam Abdul Khadir) menerangkan bahwa pendidikan memiliki lima pilar sebagai prinsip pembelajaran yang bisa diterapkan di dunia pendidikan yaitu': 1) Learning to know, bukan sebatas proses belajar di mana pelajar mengetahui dan memiliki materi informasi sebanyak-banyaknya,

${ }^{1}$ Dja'far Siddik. 2011. Konsep Dasar Ilmu Pendidikan Islam. Bandung: Citapustaka Media Perntis, h. 12.

${ }^{2}$ Rodiana A. Bakar. 2012. Pendidikan Suatu Pengantar. Bandung: Citapustaka Media Perintis, h. 14.

${ }^{3}$ Hasbullah. 2012. Dasar-Dasar Ilmu Pendidikan. Jakarta: PT. RajaGrafindo Persada, h. 4.

${ }^{4}$ Agoes Dariyo. 2013. Dasar-Dasar Pedagogi Modern. Jakarta: PT Indeks, h. 45.

${ }^{5}$ Herabuddin. 2009. Administrasi \& Supervisi Pendidikan. Bandung: CV. Pustaka Setia, h. 10 .

\footnotetext{
${ }^{6}$ Abdul Kadir. 2012. Dasar-Dasar Pendidikan. Jakarta: Kencana, h. 143-144.
} 
menyimpan dan berkembang yang tidak hanya melalui logika empiris semata, tetapi juga secara transcendental, yaitu kemampuan mengikatnya dengan nilainilai spiritual; 2) Learning to do, merupakan konsekuensi dari learning to know, kelemahan model pendidikan dan pengajaran yang selama ini berjalan adalah mengajarkan "omong" (baca teori), dan kurang menuntun orang untuk berbuat (praktik); 3) Learning to be, akan menuntun peserta didik menjadi ilmuwan sehingga mampu menggali dan menentukan nilai kehidupannya dan menentukan nilai kehidupannya sendiri dalam hidup bermasyarakat sebagai hasil belajarnya; 4) Learning to live together ini mengajarkan seseorang untuk hidup bermasyarakat dan menjadi manusia berpendidikan yang bermanfaat baik bagi diri sendiri dan masyarakatnya maupun bagi seluruh umat manusia; 5) Learning how to learn, proses belajar tidak boleh berhenti begitu saja meskipun seorang pelajar telah meyelesaikan sekolahnya.

Berdasarkan lima pilar inilah yang menjadi landasan tujuan pendidikan menurut UNESCO dalam mencapai proses pembelajaran yang dilakukan untuk menghasilkan out-put yang berkualitas di dalam lembaga pendidikan. Di Indonesia, lembaga pendidikan merupakan sebuah proses yang sangat penting dalam membangun karakter bangsa dan negara. Setiap pendidikan yang ada di Indonesia mengaplikasikan pembentukan karakter peserta didik disesuaikan dengan tujuan pendidikan.

Pendidikan IPS sebagai bidang studi yang diberikan pada jenjang pendidikan di lingkungan persekolahan, bukan hanya memberikan bekal pengetahuan saja, tetapi juga bisa memberikan bekal nilai dan sikap serta keterampilan dalam kehidupan peserta didik dimasyarakat, bangsa, dan negara dalam berbagai karakteristik. ${ }^{7}$ Tujuan utama pembelajaran IPS ialah mengembangkan potensi peserta didik agar peka terhadap masalah sosial yang terjadi dimasyarakat, memiliki sikap mental positif terhadap perbaikan segala ketimpangan yang terjadi, dan terampil mengatasi setiap masalah yang terjadi

7 Ahmad Susanto. 2013. Teori Belajar \& Pembelajaran di Sekolah Dasar, Jakarta: Kencana, h. 144. 


\section{NIZHAMIYAH}

sehari-hari yang menimpa dirinya sendiri maupun yang menimpa masyarakat. ${ }^{8}$ Dalam dunia pendidikan, guru adalah seorang pendidik, pembimbing, pelatih, dan pengembang kurikulum yang dapat menciptakan kondisi dan suasana belajar yang kondusif, yaitu suasana belajar menyenangkan, menarik, memberi rasa aman, memberikan ruang kepada siswa untuk berfikir aktif, kreatif, dan inovatif dalam mengeksplorasi dan mengelaborasi kemampuannya. ${ }^{9}$

Secara ideal, pendidik sangat dituntut agar mampu melaksanakan proses pembelajaran dengan baik dan benar. Proses pembelajaran merupakan upayaupaya yang dilakukan pendidik untuk membuat peserta didik belajar. ${ }^{10}$ Tugas pendidik tidak hanya memberikan materi pelajaran sebanyak-banyaknya, akan tetapi yang terpenting adalah bagaimana membuat peserta didik mau belajar dengan sendirinya. Tugas utama inilah yang seharusnya melandasi aktvitas setiap pendidik dalam pembelajaran.

Guru harus dapat membuat suatu pengajaran menjadi lebih efektif juga menarik sehingga bahan pelajaran yang disampaikan akan membuat siswa merasa senang dan merasa perlu untuk mempelajari bahan pelajaran tersebut. Guru harus dapat mempengaruhi, meningkatkan kecerdasan serta keterampilan siswa. Untuk itu diperlukan suatu upaya dalam rangka meningkatkan mutu pendidikan dan pengajaran, salah satunya dengan memilih model pembelajaran yang efektif. Karena proses belajar mengajar merupakan alat untuk mencapai tujuan belajar. Model yang tepat sangatlah penting dalam penyampaian pembelajaran agar memperoleh peningkatan dalam hasil belajar siswa khususnya pada pembelajaran IPS.

Berdasarkan hasil wawancara yang dilakukan kepada guru mata pelajaran IPS di MIS Al-Jam'iyatul Washliyah Desa Nagur Kec. Tanjung Kab. Serdang Bedagai bahwa nilai KKM pada kelas IV mata pelajaran IPS adalah 70, sedangkan nilai rata-rata siswa pada mata pelajaran IPS berada di bawah nilai KKM yang telah ditetapkan, dari 28 siswa 17 orang siswa yang tuntas $(60,71 \%)$, 11 siswa lagi belum tuntas $(39,28 \%)$. Hal ini menunjukkan bahwa hasil belajar

\footnotetext{
${ }^{8}$ Ibid, h. 145 .

${ }^{9}$ Rusman. 2014. Model-Model Pembelajaran. Jakarta: PT.RajaGrafindo Persada, h. 19.

${ }^{10}$ Haidir \& Salim. 2012. Strategi Pembelajaran. Medan: Perdana Publishing, h. 6.
} 


\section{NIZHAMIYAH}

yang dicapai siswa masih rendah. Berdasarkan hasil observasi yang dilakukan di kelas IV MIS Al-Jam'iyatul Washliyah Desa Nagur pada saat pelajaran IPS berlangsung, guru cenderung menggunakan metode ceramah dan penugasan, kegiatannya masih berpusat pada guru, hal ini yang menyebabkan siswa tidak aktif ketika terjadi proses pembelajaran. Untuk mengurangi adanya masalah tersebut, perlu dilakukan suatu upaya untuk mengatasinya. Salah satu upaya untuk mengatasi masalah tersebut penulis mencoba untuk menerapkan model pembelajaran make a match dan diharapkan model pembelajaran ini nantinya dapat meningkatkan hasil belajar siswa pada mata pelajaran IPS khususnya materi perkembangan teknologi komunikasi dan transportasi.

Model pembelajaran make a match merupakan model pembelajaran yang dikembangkan oleh Lorna Curran. ${ }^{11}$ Model pembelajaran make a match merupakan pembelajaran di mana setiap siswa memegang kartu soal dan kartu jawaban dan siswa dituntut untuk bekerjasama dengan siswa lain dalam menemukan kartu jawaban maupun kartu soal yang dipegang pasangannya dengan batas waktu tertentu, sehingga membuat siswa berfikir dan menumbuhkan semangat kerjasama. Hal-hal yang perlu dipersiapkan dalam pembelajaran make a match adalah kartu-kartu. Kartu-kartu tersebut terdiri atas kartu-kartu berisi pertanyaan, dan kartu-kartu lainnya berisi jawaban dari pertanyaan-pertanyaan tersebut. Model pembelajaran make a match merupakan salah satu model pembelajaran yang mampu meningkatkan keaktifan siswa di dalam kelas.

Hal ini diperkuat oleh penelitian Vivi Mairina tentang penerapan model pembelajaran make a macth pada mata pelajaran IPS kelas III SDN 07 Tiumang Dharmasaraya materi tentang denah lingkungan rumah dan sekolah serta kerja sama di lingkungan rumah, sekolah dan masyarakat. ${ }^{12}$ Penerapan model pembelajaran ini dapat meningkatkan hasil belajar siswa kelas III SDN 07 Tiumang Dharmasaraya.

\footnotetext{
${ }^{11}$ Miftahul Huda. 2012. Cooperative Learning. Yogyakarta: Pustaka Pelajar, h. 135.

${ }^{12}$ DP:ViviMariana.2013.(http://ejurnal.bunghatta.ac.id/index.php?journal=JFKIP\&page=a

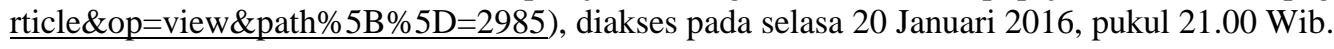




\section{NIZHAMIYAH}

Vol. IX No. 2, Juli - Desember 2019

ISSN : $2086-4205$

Berdasarkan uraian di atas maka penulis tertarik untuk mengadakan penelitian tindakan kelas yang berjudul: "UPAYA MENINGKATKAN HASIL BELAJAR SISWA PADA MATA PELAJARAN IPS MATERI PERKEMBANGAN TEKNOLOGI KOMUNIKASI DAN TRANSPORTASI MELALUI MODEL PEMBELAJARAN MAKE A MATCH DI KELAS IV MIS AL JAM'IYATUL WASHLIYAH DESA NAGUR KEC. TANJUNG BERINGIN KAB. SERDANG BEDAGAI T.P 2015/2016".

\section{B. PEMBAHASAN}

Pembahahasan hasil penelitian didasarkan pada pengamatan selama berlangsungnya proses pembelajaran dan hasil analisisnya serta hasil refleksi.

1. Pembahasan Hasil Penelitian Siklus I

Pada pembelajaran siklus I adanya peningkatan prestasi belajar siswa dibandingkan prestasi belajar sebelum diterapkan model pembelajaran make a match yaitu ditandai dengan hasil ketuntasan belajar siswa pada siklus I yaitu 17 siswa yang tuntas dan ketuntasan klasikal mencapai 60,71\%. Walaupun sudah mengalami peningkatan dibandingkan dengan sebelum diterapkan model pembelajaran make a match, tetapi nilai tes hasil belajar siklus I secara klasikal belum mencapai $85 \%$. Aktivitas siswa ketika proses pembelajaran masih dalam kategori cukup aktif karena siswa kurang termotivasi untuk memberikan pertanyaan-pertanyaan, selain itu siswa juga masih belum terbiasa menggunakan model pembelajaran make a match, sehingga siswa ribut dan bercerita bersama teman-temannya. Aktivitas guru ketika proses pembelajaran juga masih dalam kategori cukup baik.

Berdasarkan hasil pembahasan di atas, maka penelitian perlu dilanjutkan ke siklus II, dengan merefleksi pada siklus I.

2. Pembahasan Hasil Penelitian Siklus II

Berdasarkan hasil penelitian siklus I maka penelitian dilanjutkan ke siklus II. Hasil penelitian siklus II menunjukkan bahwa adanya peningkatan prestasi belajar siswa dibandingkan prestasi siswa pada siklus I yaitu ditandai dengan ketuntasan belajar, terdapat 27 siswa tuntas dalam mengikuti pembelajaran dan ketuntasan klasikal siswa mencapai $96.42 \%$. Aktivitas siswa 
dalam mengikuti pembelajaran sudah dalam kategori sangat aktif, peserta didik sangat antusias dalam mengikuti pelajaran, selain itu siswa juga tidak canggung lagi dalam melaksanakan pembelajaran dengan model pembelajaran make a match, mereka kelihatan aktif dan ceria dalam mencari pasangan kartu yang mereka peroleh. Aktivitas guru juga sudah dalam kategori baik, guru menyampaikan pelajaran dengan bantuan media gambar sehingga siswa sangat antusias dalam mengikuti pelajaran dan menggunaan model pembelajaran make a match dengan baik sehingga prestasi belajar siswa meningkat dengan ketuntasan klasikal siswa $96.42 \%$.

Berdasarkan data hasil penelitian penulis mengambil kesimpulan bahwa penggunaan model pembelajaran make a match telah berhasil meningkatkan hasil belajar siswa kelas IV MIS Al-Jam'iyatul Washliyah Nagur dan penulis berpendapat tidak perlu lagi diadakan siklus selanjutnya.

Untuk melihat peningkatan hasil belajar siswa pada tiap siklusnya dapat dilihat pada tabel berikut:

Tabel 4.8

Peningkatan Hasil Belajar Siswa

\begin{tabular}{|l|l|c|c|c|c|c|c|}
\hline \multirow{2}{*}{ No } & Nama siswa & \multicolumn{2}{|c|}{ Tes awal } & \multicolumn{2}{c|}{ Tes siklus I } & \multicolumn{2}{c|}{ Tes siklus II } \\
\cline { 3 - 8 } & & Nilai & $\begin{array}{c}\text { Keterang } \\
\text { an }\end{array}$ & Nilai & Keterangan & Nilai & Keterangan \\
\hline 1 & $\begin{array}{l}\text { Adnan } \\
\text { Adriansyah }\end{array}$ & 70 & Tuntas & 90 & Tuntas & 100 & Tuntas \\
\hline 2 & $\begin{array}{l}\text { Ardian } \\
\text { Maulana }\end{array}$ & 30 & $\begin{array}{l}\text { Tidak } \\
\text { tuntas }\end{array}$ & 60 & Tidak tuntas & 70 & Tuntas \\
\hline 3 & Bunga & 30 & $\begin{array}{l}\text { Tidak } \\
\text { tuntas }\end{array}$ & 70 & Tuntas & 80 & Tuntas \\
\hline 4 & $\begin{array}{l}\text { Cindi } \\
\text { Ramadhani }\end{array}$ & 30 & $\begin{array}{c}\text { Tidak } \\
\text { tuntas }\end{array}$ & 70 & Tuntas & 80 & Tuntas \\
\hline 5 & $\begin{array}{l}\text { Faiza } \\
\text { Khairiansya }\end{array}$ & 40 & $\begin{array}{c}\text { Tidak } \\
\text { tuntas }\end{array}$ & 50 & Tidak tuntas & 70 & Tuntas \\
\hline
\end{tabular}




\begin{tabular}{|c|c|c|c|c|c|c|c|}
\hline & $\mathrm{h}$ & & & & & & \\
\hline 6 & $\begin{array}{l}\text { Fahmi } \\
\text { Maulana }\end{array}$ & 40 & $\begin{array}{l}\text { Tidak } \\
\text { tuntas }\end{array}$ & 90 & Tuntas & 100 & Tuntas \\
\hline 7 & $\begin{array}{l}\text { Hadi } \\
\text { Wahyudi }\end{array}$ & 20 & $\begin{array}{l}\text { Tidak } \\
\text { tuntas }\end{array}$ & 60 & Tidak tuntas & 70 & Tuntas \\
\hline 8 & $\begin{array}{l}\text { Imam } \\
\text { Maliki }\end{array}$ & 40 & $\begin{array}{l}\text { Tidak } \\
\text { tuntas }\end{array}$ & 70 & Tuntas & 100 & Tuntas \\
\hline 9 & $\begin{array}{l}\text { Khairul } \\
\text { Azwar }\end{array}$ & 20 & $\begin{array}{l}\text { Tidak } \\
\text { tuntas }\end{array}$ & 80 & Tuntas & 90 & Tuntas \\
\hline 10 & Karisma & 70 & Tuntas & 90 & Tuntas & 100 & Tuntas \\
\hline 11 & $\begin{array}{l}\text { Leni } \\
\text { Mariani }\end{array}$ & 50 & $\begin{array}{l}\text { Tidak } \\
\text { tuntas }\end{array}$ & 70 & Tuntas & 90 & Tuntas \\
\hline 12 & Meiza Aulia & 30 & $\begin{array}{l}\text { Tidak } \\
\text { tuntas }\end{array}$ & 70 & Tuntas & 80 & Tuntas \\
\hline 13 & M. Agus & 40 & $\begin{array}{l}\text { Tidak } \\
\text { tuntas }\end{array}$ & 50 & Tidak tuntas & 60 & Tidak tuntas \\
\hline 14 & M. Aldi & 20 & $\begin{array}{l}\text { Tidak } \\
\text { tuntas }\end{array}$ & 70 & Tuntas & 80 & Tuntas \\
\hline 15 & $\begin{array}{l}\text { M. Mirza } \\
\text { Mahendra }\end{array}$ & 20 & $\begin{array}{l}\text { Tidak } \\
\text { tuntas }\end{array}$ & 70 & Tuntas & 90 & Tuntas \\
\hline 16 & M. Rido & 50 & $\begin{array}{l}\text { Tidak } \\
\text { tuntas }\end{array}$ & 50 & Tidak tuntas & 80 & Tuntas \\
\hline 17 & M. Rifait & 30 & $\begin{array}{l}\text { Tidak } \\
\text { tuntas }\end{array}$ & 50 & Tidak tuntas & 80 & Tuntas \\
\hline 18 & $\begin{array}{l}\text { M. Tomi } \\
\text { Syah Putra }\end{array}$ & 20 & $\begin{array}{l}\text { Tidak } \\
\text { tuntas }\end{array}$ & 60 & Tidak tuntas & 80 & Tuntas \\
\hline 19 & M. Al-Hafis & 20 & $\begin{array}{l}\text { Tidak } \\
\text { tuntas }\end{array}$ & 50 & Tidak tuntas & 90 & Tuntas \\
\hline 20 & $\begin{array}{l}\text { M. Fikri } \\
\text { Anwar }\end{array}$ & 20 & $\begin{array}{l}\text { Tidak } \\
\text { tuntas }\end{array}$ & 80 & Tuntas & 80 & Tuntas \\
\hline
\end{tabular}




\begin{tabular}{|c|c|c|c|c|c|c|c|}
\hline 21 & $\begin{array}{l}\text { M. Riski } \\
\text { Syahran }\end{array}$ & 20 & $\begin{array}{l}\text { Tidak } \\
\text { tuntas }\end{array}$ & 50 & Tidak tuntas & 90 & Tuntas \\
\hline 22 & $\begin{array}{l}\text { Nela } \\
\text { Akmalia }\end{array}$ & 30 & $\begin{array}{l}\text { Tidak } \\
\text { tuntas }\end{array}$ & 80 & Tuntas & 90 & Tuntas \\
\hline 23 & Nurhasanah & 20 & $\begin{array}{l}\text { Tidak } \\
\text { tuntas }\end{array}$ & 60 & Tidak tuntas & 80 & Tuntas \\
\hline 24 & $\begin{array}{ll}\text { Siti } & \text { Nurul } \\
\text { Aini } & \end{array}$ & 50 & $\begin{array}{l}\text { Tidak } \\
\text { tuntas }\end{array}$ & 80 & Tuntas & 90 & Tuntas \\
\hline 25 & $\begin{array}{l}\text { Suci } \\
\text { Ramadhani }\end{array}$ & 30 & $\begin{array}{l}\text { Tidak } \\
\text { tuntas }\end{array}$ & 70 & Tuntas & 90 & Tuntas \\
\hline 26 & Ulan Sari & 40 & $\begin{array}{l}\text { Tidak } \\
\text { tuntas }\end{array}$ & 80 & Tuntas & 90 & Tuntas \\
\hline 27 & Vera Novita & 40 & $\begin{array}{l}\text { Tidak } \\
\text { tuntas }\end{array}$ & 70 & Tuntas & 80 & Tuntas \\
\hline 28 & Zahra Aulia & 30 & $\begin{array}{l}\text { Tidak } \\
\text { tuntas }\end{array}$ & 60 & Tidak tuntas & 80 & Tuntas \\
\hline & Jumlah & 950 & - & 1900 & - & 2360 & - \\
\hline & Rata-rata & $\begin{array}{l}33.9 \\
3\end{array}$ & - & $\begin{array}{l}67.8 \\
5\end{array}$ & - & 84.23 & - \\
\hline
\end{tabular}

Mencermati tabel 4.8 terjadi peningkatan yang signifikan pada hasil belajar siswa pada mata pelajaran IPS materi perkembangan teknologi komunikasi dan transportasi sebelum dan sesudah diterapkan model pembelajaran make a match. Hal ini terlihat jelas dimana saat melakukan tes awal (pretest), kemampuan siswa kurang dengan nilai rata-rata 33,93 dan hanya 2 orang siswa $(7,14 \%)$ yang berada pada level ketuntasan belajar. Selanjutnya setelah melakukan pembelajaran dengan menerapkan model pembelajaran make a match pada siklus I hasil belajar siswa meningkat dari sebelumnya dengan nilai rata-rata 67,85 dan terdapat 17 orang siswa $(60,71 \%)$ berada pada level ketuntasan belajar.

Namun pembelajaran pada siklus I belum optimal karena siswa belum seluruhnya termotivasi dalam mengikuti pelajaran dan siswa pun masih malu- 
malu dan canggung dalam melaksanakan pembelajaran melalui model pembelajaran make a match selain itu ketuntasan klasikal siswa juga belum memenuhi standart yang ditentukan penulis yaitu $85 \%$. Maka berdasarkan refleksi pada siklus II hasil belajar siswa mengalami peningkatan dari siklus I ke siklus II. Pada hasil tes siklus II diperoleh nilai rata-rata 84,23 dan 27 siswa $(96.42 \%)$ berada pada level ketuntasan. Peningkatan frekuensi ketuntasan belajar siswa pada materi perkembangan teknologi komunikasi dan transportasi lebih jelasnya lagi dapat dilihat pada grafik berikut:

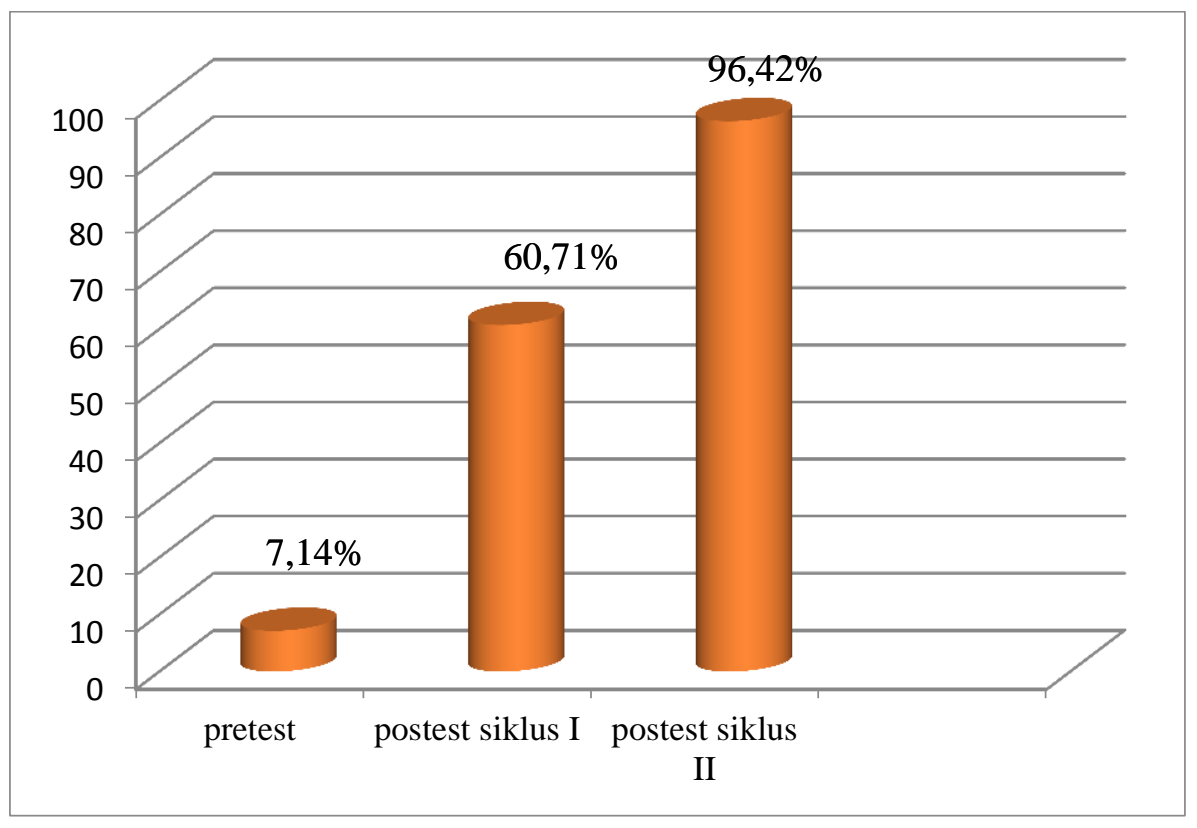

\section{Gambar 4.4 Grafik Peningkatan Ketuntasan Hasil Belajar Siswa}

Keterangan gtafik:

Frekuensi Ketuntasan Belajar Pada Pretest (2 Siswa atau 7,14\%)

Frekuensi Ketuntasan Belajar Pada tes siklus I (17 Siswa atau 60,71\%)

Frekuensi Ketuntasan Belajar Pada tes Siklus II ( 27 Siswa atau 96,42\%).

Analisis hasil temuan yang dapat penulis paparkan adalah terjadinya peningkatan hasil belajar siswa di mana pada tes awal (pretest) frekuensi ketuntasan sebesar $7,14 \%$ sedangkan pada tes yang dilakukan pada siklus I ketuntasan yang diperoleh siswa sebesar $60,71 \%$ dan pada tes terakhir yang dilakukan pada siklus II ketuntasan yang diperoleh siswa sebesar 96,42\%. 


\section{NIZHAMIYAH}

Berdasarkan penjelasan di atas dapat diambil kesimpulan bahwa terjadinya peningkatan hasil belajar siswa dengan menerapkan model pembelajaran make a match pada mata pelajaran IPS materi perkembangan teknologi komunikasi dan transportasi di kelas IV MIS Al-Jam'iyatul Washliyah Nagur. Kec. Tanjung Beringin. Kab. Serdang Bedagai. Hal ini sesuai dengan penelitian terdahulu yang dilakukan oleh Aisyah Br. Padang bahwa hasil penelitian menyimpulkan penerapan model pembelajaran make a match dapat meningkatkan hasil belajar siswa pada mata pelajaran Agama Islam. ${ }^{13}$ Selain itu senada juga dengan penelitian yang dilakukan Vivi Mairina, menyimpulkan bahwa pembelajaran melalui model make a match dapat meningkatkan hasil belajar siswa pada mata pelajaran IPS. ${ }^{14}$

\section{PENUTUP}

Berdasarkan hasil penelitian dan pembahasan yang disajikan, maka dapat diperoleh kesimpulan sebagai berikut:

1. Hasil belajar siswa sebelum diterapkannya model pembelajaran make a match atau disebut juga dengan pra tindakan ketuntasan siswa hanya mencapai 7,14\% atau 2 orang siswa yang tuntas dengan nilai rata-rata 33,93.

2. Penerapan model pembelajaran make a macth pada mata pelajaran Ilmu Pengetahuan Sosial (IPS) dengan cara memberikan kartu-kartu, yang mana pada kartu-kartu tersebut siswa diminta untuk memikirkan jawaban atau pertanyaan dari kartu yang diperoleh, sehingga siswa berfikir dan menumbuhkan semangat kerjasama dan siswa terlihat aktif dalam proses pembelajaran. Melalui kartu-kartu tersebut dengan mengikuti langkahlangkah model make a macth yang telah dijelaskan oleh guru.

3. Ketika menggunakan model pembelajaran make a match pada siklus I hasil belajar siswa mengalami peningkatan dengan menunjukkan ketuntasan siswa $60,71 \%$ atau 17 siswa yang tuntas dengan nilai rata-rata 67,85 dan

13 Aisyah Br. Padang, 2013. Penerapan Model Pembelajaran Make a match Untuk Meningkatkan Hasil Belajar Siswa Pada Mata Pelajaran Agama Islam. Krispsi, h. 63.

${ }^{14}$ Vivi Mairina dkk. 2013. Penerapan Model Pembelajaran Tipe Make a match Untuk Meningkatakn Hasil Belajar Siswa Pada Mata Pelajaran Ilmu Pengetahuan Sosial, Jurnal Pendidikan, h. 10. 
pada siklus II ketuntasan klasikal siswa meningkat menjadi 96,42\% atau 27 siswa yang tuntas dengan nilai rata-rata 84,23.

\section{DAFTAR PUSTAKA}

Aidah, Asnil \& Irwan. 2013. Tafsir Tarbawi. Bandung: Citapustaka Media.

Arsyad, Azhar. 2007. Media Pembelajaran. Jakarta: PT RajaGrafindo Persada.

Aqib, Zainal. 2010 ( et al ). Penelitian Tindakan Kelas. Bandung: Yrama Widya.

Aunurrahman. 2012. Belajar dan Pembelajaran. Bandung: Alfabeta.

Bakar, Rosdiana. A. 2012. Pendidikan Suatu Pengantar. Bandung: Citapustaka

Media Perintis.

Bobbi Deporter, Mark Reardon, Sarah Singer-Nourie. 2010. Quantum Teaching. Bandung: Kaifa.

Dariyo, Agoes. 2013. Dasar-Dasar Pedagogi Modern. Jakarta: PT Indeks.

Dimyati, Johni,. 2013. Metodologi Penelitian Pendidikan Dan Aplikasinya Pada Pendidikan Anak Usia Dini (PAUD). Jakarta: Kencana.

Haidir \& Salim. 2012. Strategi Pembelajaran. Medan: Perdana Publishing.

Hasbullah. 2012. Dasar-Dasar Ilmu Pendidikan. Jakarta: PT. RajaGrafindo Persada.

Herabuddin. 2009. Administrasi \& Supervisi Pendidikan. Bandung: CV. Pustaka Setia.

Huda, Miftahul. 2012. Cooperative Learning. Yogyakarta: Pustaka Pelajar.

Idris, Jamaluddin. 2011. Teknik Evaluasi Dalam Pendidikan dan pembelajaran. Bandung: Citapustaka Media Perintis.

Imas, Kusniasih \& Berlin Sani. 2015. Ragam Pengembangan Model Pembelajaran. Kata Pena.

Istarani. 2012. 58 Model Pembelajaran Inovatif. Medan: Media Persada. 